\title{
Food and feeding behaviours of Spotfin Swamp Barb Puntius sophore (Hamilton, 1822) of Singhiya River, Biratnagar
}

\author{
${ }^{1}$ Anjali Risal*, ${ }^{1}$ Samjhana Shrestha and ${ }^{2}$ Vinod Kumar Mahaseth \\ ${ }^{1}$ Department of Zoology, Post Graduate Campus, Tribhuvan University, Biratnagar \\ ${ }^{2}$ Mahendra Morang Adarsha Multiple Campus, Tribhuvan University, Biratnagar \\ *E-mail: anjalirisal@gmail.com
}

\begin{abstract}
The present work attempt to present a novel approach about the food and feeding habits of Puntius sophore collected from Singhiya River, Biratnagar. For the study 120 specimens were collected on the monthly basis from March to August 2019, direct from the river with the help of local fisherman. On the basis of percentage of occurrence of gut content analysis, the most preferred food item was Green algae $(40.6 \%)$ followed by diatoms $(16.10 \%)$, crustaceans $(13.50 \%)$, protozoan $(9.20 \%)$, detritus and debris $(8.40 \%)$, insect larva $(7.70 \%)$ and rotifers $(4.50 \%)$. Relative gut length was the lowest at size 4.4-5.1 cm SL and the highest value at size 9.3-10 cm SL. Gastro somatic index was highest peak at the size of 4.4-5.1 cm SL, which indicate the voracious nature of fish at smaller size. The standard length and body weight show a positively significant with alimentary canal length $(\mathrm{r}=0.878)$ and alimentary canal weight $(r=0.86 .4)$, respectively. The food and feeding behavior of this fish showed that it is omnivores in nature.
\end{abstract}

Key words: Food and feeding behaviour, Gastrosomatic index, Gut content, Relative gut length,

\footnotetext{
DOI: http://doi.org/10.3126/on.v17i1.33989

Manuscript details: Received: 15.10.2019/ Accepted: 25.11.2019

Citation: Risal, A., S. Shrestha and V.K. Mahaseth 2019. Food and feeding behaviours of Spotfin Swamp Barb Puntius sophore (Hamilton, 1822) of Singhiya River, Biratnagar.Our Nature 17 (1): 31-36. DOI: http://doi.org/10.3126/on.v17i1.33989

Copyright: Risal, Shrestha and Mahaseth 2019. Creative Commons Attribution - Non Commercial 4.0 International License.
}

\section{Introduction}

Feeding is one of the main concerns of daily living in fishes, in which fish devotes large portion of its energy in searching for food. Like other organism fish also depends on energy received from its food to perform its biological process such as growth, development, reproduction and other metabolic activities thus the basic function of fish are such as growth, development, and reproduction which depend upon the food taken by them. The food and feeding habit of fish depends upon various factors such as size of fish, season, various ecological factor and different food substances present in water body (Hynes, 1950). Knowledge of food and feeding habit of fish is important aspect for understanding their general biology including important aspect such as growth, breeding and migration (Golikatte and Bhat, 2011). Puntius sophore (Hamilton, 1822) is a Tropical fresh water fish belonging to genus Puntius.

It is a deep bodied fish having distinct orange golden spot below the eye. It lives in small ponds, lakes and overgrown lowland rivers in which the water flows very slowly. It is widely distributed throughout Nepal. It occurs in India, Myanmar, Pakistan and Srilanka (Shrestha, 2008). Knowledge of feeding habit of a particular fish species is very important since it plays a vital role in fisheries biology (AlHussaini and Kholy, 1953; Gheyas, 1998; Islam et al., 2004). 


\section{Materials and methods}

Three site of Singhiya River (Latitude $26^{\circ} 29^{\prime} 7^{\prime \prime}$ Longitude $\left.87^{\circ} 17^{\prime} 40^{\prime \prime} \mathrm{E}\right)$ were selected for the sample collection, sampling station A (Hanuman Mandir) lies on 28028'01.8' $\mathrm{N}$ and 87017' 26.2"E, station B (Hatkhola) lies $260 \mathrm{~N}$ and 87017' 47.9"E and station C (Jatuwa) lies 26026' $13 . \mathrm{g}^{\prime} \mathrm{N}$ and 87018' 00.4"E of the Morang district. Samples were collected early in the morning 810 am twice a month from March to August 2019 with the help of local fisherman. Just after collection $10 \%$ formalin solution was injected into the gut of all the fishes in order to stop digestion of food items.

Before the dissection of fish, total length, standard length and body weight of each specimen was measured and recorded. Fishes were then dissected so as to exposé their digestive organ. The entire alimentary canal from oesophagus to anus was removed then weight was measured with digital balance. The removed alimentary canal was placed in a dissecting tray then the intestine was decoiled. The gut length (oesophagus to anus) was measured with measuring tape and recorded. The gut of the fishes was then dissected with the help of a simple scissors. The gut contents were taken into a Petri dish, after that the food items were identified under binocular microscope (Magnification $5 \mathrm{X}, 10 \mathrm{X})$ by using identification key given by Ward and Whipple (1959), Needham and Needham (1962). Similar method of Hynes (1950) and Pillay (1954) was followed for estimation of the percentage composition of food items.

\section{Relative gut length}

Relative gut length is the useful index used to know about the nature of food and feeding habit. (Syehiro, 1941) reported a high degree of correlation between the food habits and relative length of gut (RLG) of fishes. The value of relative gut length can be calculated simply by taking the ratio of gut length and body length.

According to (Al Hussaini, 1949)

$\mathrm{RLG}=\mathrm{GL} / \mathrm{TL}$

$\mathrm{RLG}=$ Relative gut length

$\mathrm{GL}=$ Length of the gut

$\mathrm{TL}=$ Total body length

\section{Gastro somatic index}

Gastro-somatic index was calculated by using the method followed by (Bhatnagar and Karamchandani, 1970) as follows:

$$
\text { GSI }=\frac{\text { Weight of gut }}{\text { Weight of fish }} \times 100
$$

\section{Data analysis}

Relationship between the alimentary canal length and standard length and alimentary canal weight and total body weight was determined by linear regression analysis

$\mathrm{Y}=\mathrm{a}+\mathrm{bx}$

Where, $b=$ exponent coefficient

$\mathrm{a}=$ coefficient related to body form

Scatter plot diagrams were plotted for relation-ship between the alimentary canal length and standard length and alimentary weight and body weight and coefficient of correlation (r) was calculated by standard statistical formula.

\section{Result and discussion}

\section{Gut content analysis of Puntius sophore}

The percentage composition of food items in the gut of Puntius sophore as observed in different months has been summarized in the table 1 . The guts content of $P$. sophore have been group into 7 broad categories i.e., Green algae, diatoms, protozoan, crustaceans, rotifers, insect larvae and detritus and debris. It was seen that there were considerable variations in the percentage of different food items during different months of the year. Green algae showed the highest percentage (44.4) occurrence in July and that of lowest (29.2) in August. Percentage occurrence of diatoms was highest in June (25) and lowest in July (7.4). The highest percentage of protozoan occurred in May (16.6) and was totally nil during June and July. The highest percentage of occurrence of crustaceans in the gut was in August (37.5) and lowest in April (5.9). The highest percentage of rotifers noticed in June (12.5) and was totally nil during August. The highest percentage of insect larvae was observed in July (18.5) and was totally nil in April. Percentage occurrence of detritus and debris was highest in April (14.7) and lowest in July (3.7). 


\section{Our Nature | December 2019 | 17 (1): 31-36}

Seasonal variation showed a slight variation in feeding habit which might be due to fluctuation in the availability of different food items in different season.

The most preferred food for $P$. sophore was Green algae $(40.60 \%)$ followed by diatoms $(16.10 \%)$, crustaceans $(13.50 \%)$, protozoan (9.20\%), detritus and debris $(8.40 \%)$, insect larva $(7.70 \%)$ and rotifers $(4.50 \%)$ as shown in figure
1. Same result was also revealed by (Hossain et al., 2016) showing that the phytoplankton was dominant food for $P$. sarana with highest percentage of Chlorophyceae (22.39). Mondol et al., (2005) also reveals that $P$. gonionotus is regarded as planktivores fish feeding mostly on phytoplankton. Deshmukh and Shillewar (2018) Also concluded that Phytoplankton was the most preferred food for $P$. sarana i.e., $55.45 \%$.

Table 1. Percentage of major food items found in the Gut of Puntius sophore

\begin{tabular}{lllllll}
\hline & March & April & May & June & July & August \\
\hline Green algae & $43.2 \%$ & $44.1 \%$ & $37.5 \%$ & $43.7 \%$ & $44.4 \%$ & $29.2 \%$ \\
Diatoms & $23.3 \%$ & $17.6 \%$ & $16.6 \%$ & $25 \%$ & $7.4 \%$ & $8.3 \%$ \\
Protozoan & $13.3 \%$ & $14.7 \%$ & $16.6 \%$ & - & - & $4.2 \%$ \\
Crustaceans & $6.6 \%$ & $5.9 \%$ & $8.3 \%$ & $6.2 \%$ & $18.5 \%$ & $37.5 \%$ \\
Rotifers & $3.3 \%$ & $2.9 \%$ & $4.1 \%$ & $12.5 \%$ & $7.4 \%$ & - \\
Insects larvae & $3.3 \%$ & - & $8.3 \%$ & $6.2 \%$ & $18.5 \%$ & $12.5 \%$ \\
Detritus and Debris & $6.6 \%$ & $14.7 \%$ & $8.3 \%$ & $6.2 \%$ & $3.7 \%$ & $8.3 \%$
\end{tabular}

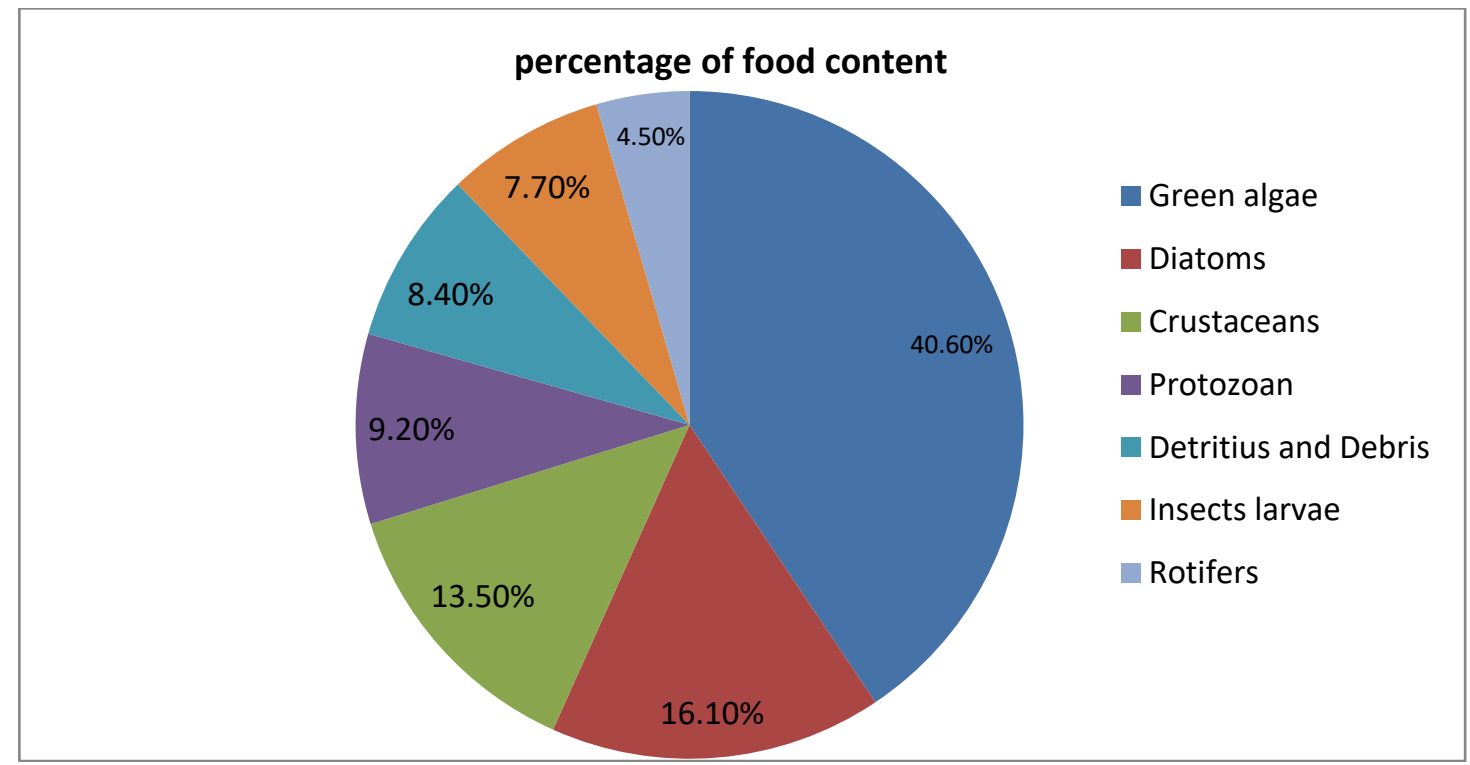

Fig 1. Percentage of occurrence food items found in the gut of Puntius sophore

\section{Relative gut length}

The relative gut length of Puntius sophore varied from 2.736 to 4.369 within the size range of $4.4-10 \mathrm{~cm}$ respectively. Relative gut length of $P$. sophore was lowest at size 4.4-5.1 $\mathrm{cm}$ standard length and gradually increased from 5.8-6.5 $\mathrm{cm} \mathrm{SL}$ and with highest value at size $9.3-10 \mathrm{~cm}$ SL as shown in figure 2. Similar result was obtained in $P$. ticto by (Koundal et al., 2013) in which RLG was lowest at size 30-35 mm SL showing a increasing trend with highest at size 50-55 $\mathrm{mm}$ SL. 


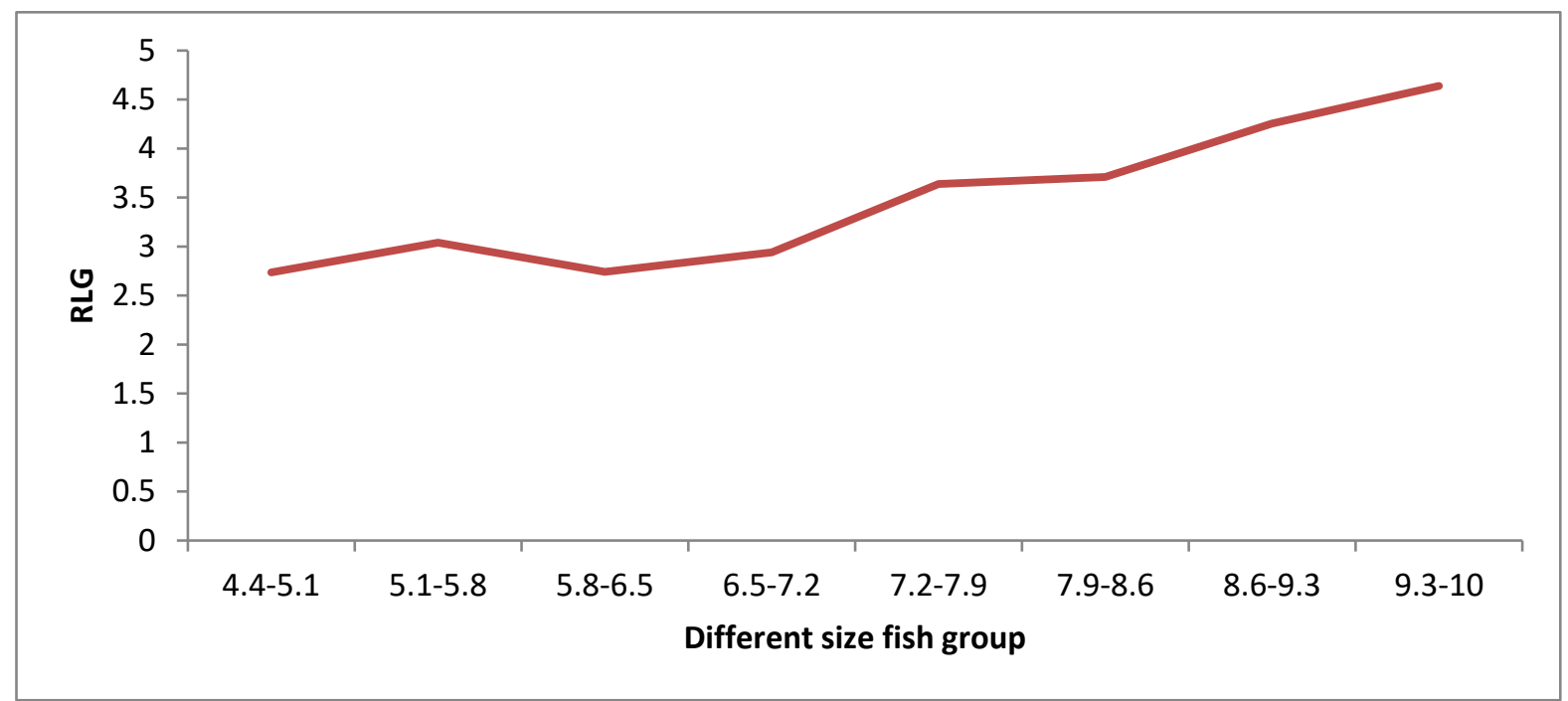

Fig 2. Relative gut length with standard length of Puntius sophore

\section{Gastrosomatic index}

Gastrosomatic index in P. sophore varied from 4.0320 to 7.275 within the size $4.4-10 \mathrm{~cm}$. GSI was obtained highest peak at the size of 4.4$5.1 \mathrm{~cm}$ SL gradually decreased and lowest at the size between 5.8-6.5 cm SL as shown in figure 3. This indicates the voracious feeding habit at smaller size fish. Similar result was obtained in P. ticto by (Koundal et al., 2013) in which GSI was highest at size $30-35 \mathrm{~mm} \mathrm{SL}$ and lowest at size 50-55 mm SL.

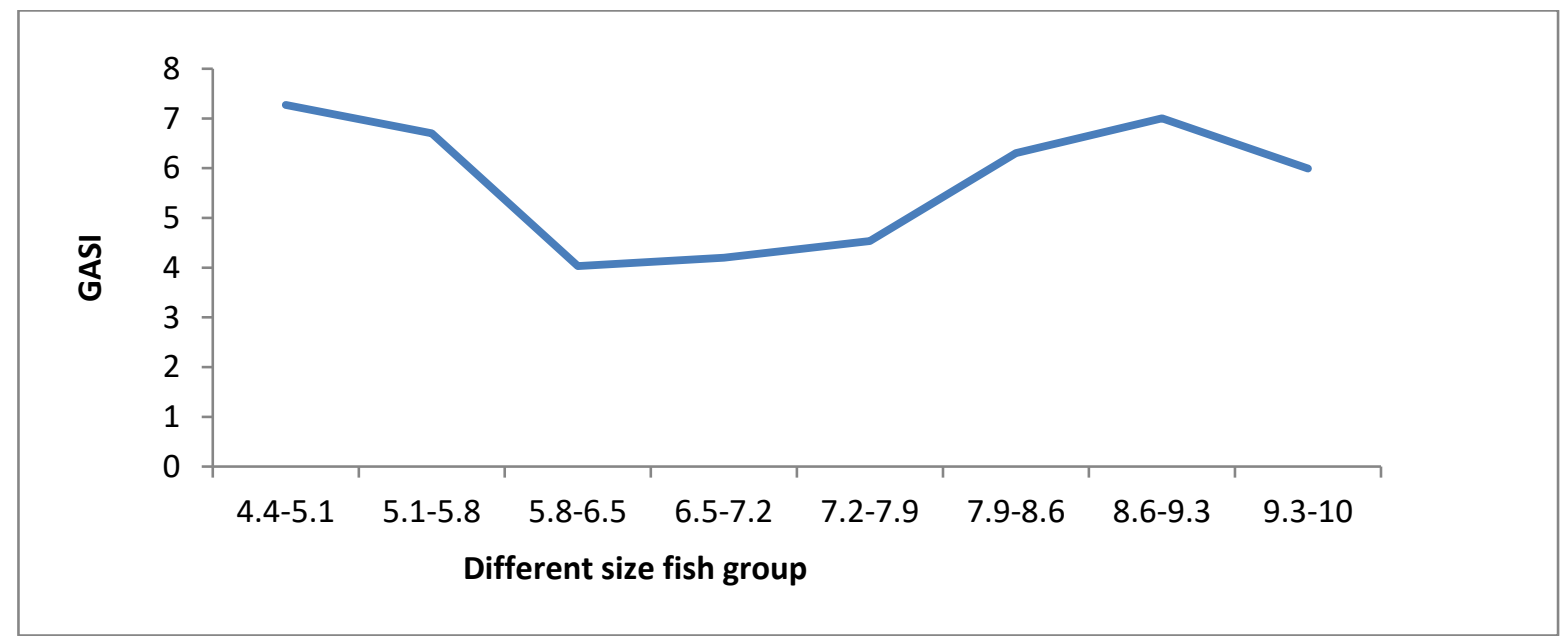

Fig 3. Gastro somatic index of different size group of Puntius sophore

\section{Alimentary canal length and standard length of Puntius sophore}

Standard length of $P$. sophore shows an increasing trend with increase in alimentary canal length as shown in figure 4.

When alimentary canal lengths were plotted on co-ordinate (y-axis) against those of standard lengths on co-ordinate (x-axis) it gave straight line shown in figure 4 .
Regression equation for $P$. sophore is; Alimentary canal length - Standard length $\mathrm{AL}=6.5446 \mathrm{SL}-21.919$

Where, $\mathrm{AL}=$ Alimentary canal length $\mathrm{SL}=$ Standard length

The regression value $b$ is found to be 6.5446 . Results for alimentary canal length and standard length is highly correlated i.e., $\mathrm{r}=0.8789$ 


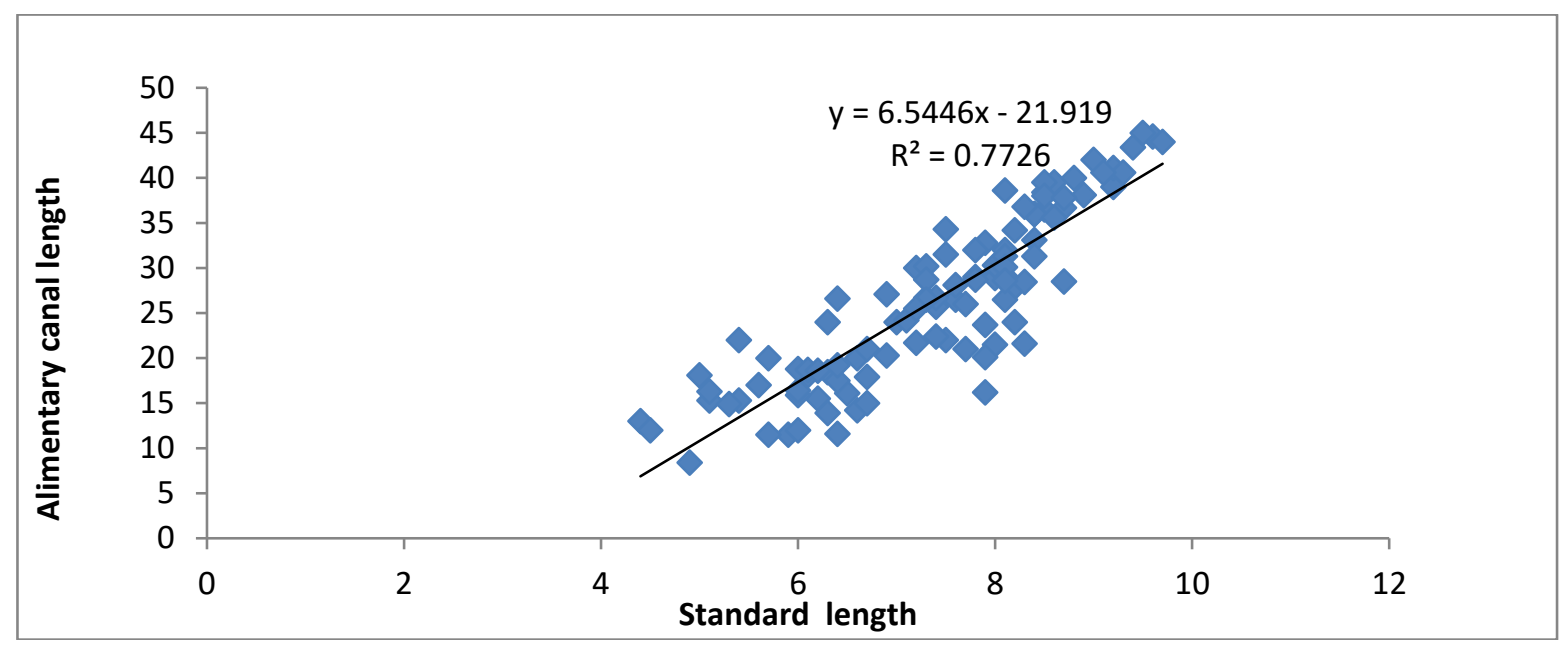

Fig 4. Alimentary canal length and standard length of Puntius sophore

\section{Alimentary canal weight and Total body weight of Puntius sophore}

Total weight of $P$. sophore shows an increasing trend with increase in alimentary canal weight as shown in figure 5 .

When the values of alimentary canal weight were plotted on co-ordinate (x-axis) against those of body weight on co-ordinate (y-axis) it gave straight line as shown in figure 5.
Regression equations for $P$. sophore is; Alimentary canal weight - Total body weight $\mathrm{AW}=0.08 \mathrm{TW}-0.1315$

Where, $\mathrm{TW}=$ Total weight

$\mathrm{AW}=$ Alimentary canal weight

The regression value $\mathrm{b}$ found to be 0.08 . Results for Alimentary canal weight and total body weight is highly correlated i.e., $r=0.86$

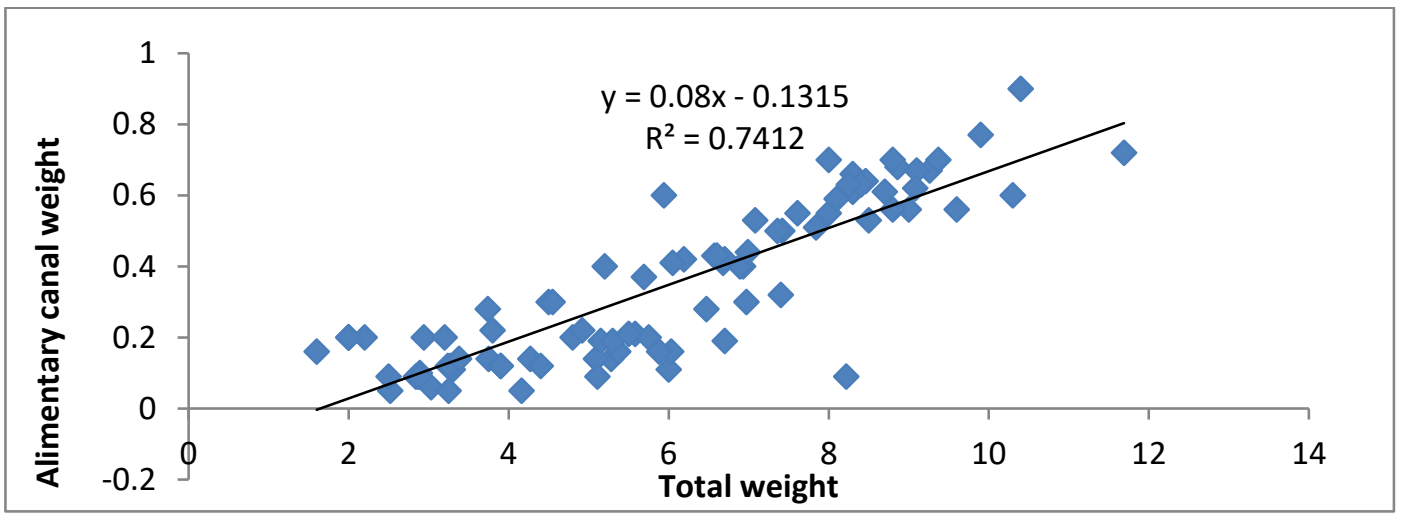

Fig 5. Alimentary canal weight and Total body weight of Puntius sophore

\section{Conclusion}

The present study on "Food and feeding behaviours of Puntius sophore (Hamilton, 1822)" indicated that Puntius sophore is an omnivore fish consuming highest percentage of Algae (36.10).

\section{Acknowledgement}

Authors like to acknowledge the local fishermen who continuously helped us to collect the fish from river.

\section{References}

Al-Hussaini, A.H. and M. Kholy 1953. Studies of anatomy and histology of the alimentary canal of Scarus serdidus (Klunz). Bull. Inst. Egypt. 32: 123-132.

Al-Hussaini, A.H. 1949. On the functional morphology of the alimentary tract of some fishes in relation to differences in their feeding habits. Quart. Micr. Sc 9(2): 1.

Bhatnagar, G.K. and S. J. Karamchandani 1970. Food and feeding habits of Labeo fimbriatus (Bloch) in river Narbada near 
Hoshangabad (M.P). Journal of Inland Fisheries Society of India 2: 30-50.

Deshmukh, M.M. and K.S. Shillewar 2018. Food and feeding habits of puntius sarana (Hamilton) from Godavari, Nanded, Maharashtra state. International Journal of Life Sciences Research 6(3): 328-330 ISSN 2348-3148.

Gheyas, S. 1998. On some aspects of digestion in Carps. Acta. Biol. 7 (31): 22-34.

Golikatte R. G. and G. Bhat 2011. Food and Feeding Habits of the Whipfin Silver Biddy Gerres FIlamentosus from Sharavati estuary, Central West Coast of India. World Journal of Science and Technology 1(2): 29-33.

Hossian, M.S., A. Roy and L. Rahman 2016. Food and feeding habit of Bele Glossogobius giuris (Hamilton and Buchannan, 1822) Collected from Mithamain Haor of Kishoreganj districts, northeastern Bangladesh. International Journal of Fisheries and Aquatic Studies 4(5): 84-88.

Hynes, H. B. N. 1950. The food of fresh water Gasterosteus aculeatus and Pygesteus pungitus, with a review of methods used in studies of the food of fishes. J. Anim. Ecol. 19: 36-58.

Islam, M. N., S. Parvin, F. Hyder, F.A. Flowara and A. Masud 2004. Food and feeding habit of juvenile Channa punctatus (Bloch) from a semi closed water body in chalan beel floodplain, Bangladesh. Journal of Biological Sciences 4(3): 352-356.

Koundal, A., S. Koundal, I. Sharma and R. Dhanze 2013. Relative gut length and Gastro somatic index of six Hill stream fishes, Himachal Pradesh, India. J. Env. Bio-Sci 27 (1): 11-18.

Mondol, M.R., S. Dewan, M.A. Hossoin, M. Asaduzzaman, M.A. Islam, and U.A. Rozario 2005. Food and feeding habits of Puntius goninotus (Thai Sarpunti) in rice field Pakistan. Journal of biological sciences 8(3): 386-395.

Needham, J.G. and P.R. Needham (1962). A Guide to the Study of Fresh Water Biology Holden Day Ins. San Francisco, USA, 108

Pillay, T.V.R. 1954. The biology of the grey mullet (Mugil cephalus L.). Proc. Nat. Inst. Sci. India 20 (2): 18- 217.

Shrestha, T.K. 2008. Ichthyology of Nepal. Systematic Account and description of fishes ISBN: 978-9937-2-0653-2, pp 80.

Shyehiro, Y. 1941, A study of the digestive system and feeding habits of fish Jap. $J$. Zool 10: 303.

Ward, H.B. and G.C. Whipple 1959. Fresh-water Biology. 2nd ed.,-WT Edmondson, ed. John Wiley and Sons, New York. 